\title{
Is Autonomy a Universal Value of Human Existence? Scope of Autonomy in Medical Practice: A Comparative Study between Western Medical Ethics and Islamic Medical Ethics
}

\author{
Rathor MY, Azarisman Shah MS, Hasmoni MH \\ Department of Internal Medicine, Faculty of Medicine, International Islamic University Malaysia, Kuantan, \\ Pahang, Malaysia
}

\begin{abstract}
The practice of contemporary medicine has been tremendously influenced by western ideas and it is assumed by many that autonomy is a universal value of human existence. In the World Health Report 2000, the World Health Organization (WHO) considered autonomy a "universal" value of human life against which every health system in the world should be judged. Further in Western bioethics, patient autonomy and self -determination prevails in all sectors of social and personal life, a concept unacceptable to some cultures. In principle, there are challenges to the universal validity of autonomy, individualism and secularism, as most non-Western cultures are proud of their communal relations and spiritualistic ethos and, thereby imposing Western beliefs and practices as aforementioned can have deleterious consequences. Religion lies at the heart of most cultures which influences the practice patterns of medical professionals in both visible and unconscious ways. However, religion is mostly viewed by scientists as mystical and without scientific proof. Herein lies the dilemma, whether medical professionals should respect the cultural and religious beliefs of their patients? In this paper we aim to discuss some of the limitations of patient's autonomy by comparing the process of reasoning in western medical ethics and Islamic medical ethics, in order to examine the possibility and desirability of arriving at a single, unitary and universally acceptable notion of medical ethics. We propose a more flexible viewpoint that accommodates different cultural and religious values in interpreting autonomy and applying it in an increasingly multilingual and multicultural, contemporaneous society in order to provide the highest level of care possible.
\end{abstract}

KEYWORDS: Informed consent; autonomy; biomedical ethics; cultural conflict; paternalism.

\section{INTRODUCTION}

The practice of medicine is a universal phenomenon and in today's globalized world, clinicians encounter patients from all walks of life. Although Westernized medical practices are typically accepted in a majority of the world, complementary and alternative medicine (CAM) or traditional indigenous systems of medicine as well as spiritual treatment still hold precedence in vast areas of the world and have gained popular recognition even in the West in recent years, but are seldom discussed in the literature on bioethics. ${ }^{1}$

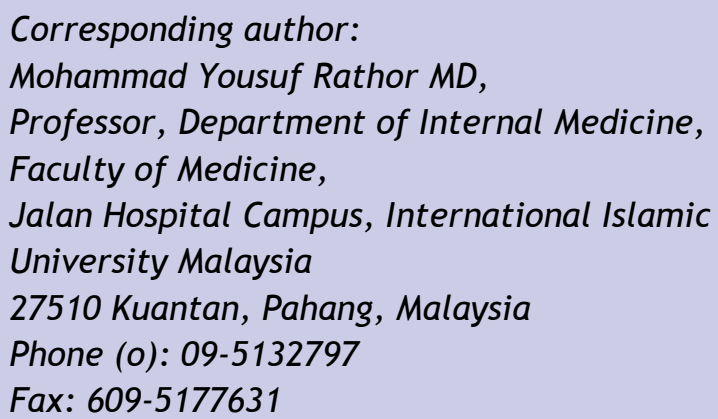

In the World Health Report 2000, the World Health Organization (WHO) considered autonomy a "universal" value of human life against which every health system in the world should be judged. ${ }^{2}$ The principle of autonomy has become absolute, taking precedence over all other values such as beneficence. Autonomy is an important ethical principle that is basic to human dignity, however the obligation to respect autonomy is not absolute as there are challenges to its universal validity. ${ }^{3,4}$ Since the beginning of the recorded history of human civilization, religious beliefs and practices have been intertwined with the practice of medicine, which is mostly viewed by scientists as mystical and without scientific proof. Here in lies the dilemma, whether medical professionals should respect the cultural and religious beliefs of their patients, despite their perceived detrimental influence or seek to supplant them with modern rational and empirical scientific research and or evidence-based medicine despite their abject refusal. History recapitulates many instances when there have been intense and sometimes fanatical debates resulting from people's differences in 
ethical, social and religious beliefs on the one hand, and medical practice on the other. ${ }^{5}$ Despite modernity and the forces of secularization, religion persists and lies at the heart of most cultures. Many religions provide for reasoning about moral issues and arriving at a correct decision. Patients and medical professionals embody the engagement of religion with modern medicine on a daily basis, which influences their practice patterns in both visible and unconscious ways. ${ }^{6,7}$ The three monotheistic religions (Judaism, Christianity and Islam) share essentially the same code of morality and have largely similar bioethical values. They are the main source of health ethics in large areas of the world.

Islam is one of the largest religions in the world with, approximately 1.5 billion followers worldwide, the majority of which live in Islamic countries and an appreciable number live in non-Islamic states. In both environments they maintain a 'code of conduct' that provides guidance in all key aspects of life. However, the allure of material wealth, individualism, consumerism and sexual freedom has threatened to draw sections of Muslim youth and educated elite away from the Muslim religion creating dissension and discord. Muslims are presently caught at a crossroad between the traditional and the modern values. They view themselves as counter-forces to cultural domination by the West. Abortion, biotechnical parenting, the end of life issues, assisted suicide, and euthanasia are some of the moral controversies faced by Muslims nowadays.

In this paper we aim to review the literature regarding the principle of autonomy and its practical application to current medical issues by comparing the process of reasoning in western medical ethics and Islamic medical ethics, in order to examine the question of the possibility and desirability of a universal medical ethics.

\section{From Hippocratic medical ethics to contemporary} medical ethics

The practice of contemporary medicine has changed over the years and will continue to change as medicine advances. Since time immemorial, medicine has been considered as a "noble profession" and has been heavily influenced by the moral and religious values of those who practise them. The ability to heal was considered as a divine gift and back then, a physician's station was considered to be next only to God. A physician was a friend, philosopher, learned reader and general guide in whom many could safely confide their secrets. Many took up this profession as a vocation with a strong feeling to serve humanity. In the Indian tradition, a young student was accepted into medical training only after careful assessment of his/her competence and suitability. The initiation ceremony was a grand ritual held in the presence of students and teachers alike wherein the preceptor would solemnly issue directives which the newcomer was obliged to accept. Al Ghazali, an eleventh century Muslim theologian and philosopher, considers the profession of medicine as "FardhuKifayah" a duty upon the society as a whole which is lifted upon the initiation of a chosen few.

The principle of beneficence, associated with nonmalfeasance, has oriented medical practice for over 2500 years. Since the very beginning, the relationship between physicians and patients has followed the Hippocratic pledge, "I will use treatment to help the sick according to my ability and judgment, but will never use it to injure or wrong them." Generations of physicians have pledged to do their best to protect patients from harm, and restore them to health. Physician-patient relationship was based on mutual trust and society acknowledged that physicians had the medical knowledge, relied on their professional opinion and expertise and followed their advice without question.

For centuries, paternalism and beneficence were the main principles sustaining medical ethics. ${ }^{8}$ However, immediately after the World War II, the public became aware of dreadful medical experiments, conducted by Nazi doctors in concentration camps. Thousands of prisoners were subjected to experimentation including unsafe and lethal drug testing, against their will. This led to the creation of Nuremberg Code of Ethics in 1947 and the notion of informed consent was born. Ever since, the scientific community has continued to revise such principles in order to ensure the ethical treatment of patients.

In the 1960s some democratic societies began to focus on individual rights, and autonomy was recognized in law and in medicine. 9,10 The United States was the cradle for the birth of this bioethical movement. Centuries-old professional ethics founded on mutual trust between physicians and patients was replaced with autonomy, enabling patients to be included in the decision-making process following revelation of relevant information. The Hippocratic Oath became increasingly criticised and there has been calls for its outright rejection, with claims that it represented a paternalistic "doctor knows best" approach to medicine. ${ }^{11}$ This perceptible change is well illustrated by a comparison of the ethical codes for the American Medical Association (AMA) over the last two centuries. ${ }^{12}$

In article II of the 1847 AMA ethical code entitled "Obligations of patients to their physicians", the following statement was found in section 6:

"The obedience of a patient to the prescriptions of his physician should be prompt and implicit. He should never permit his own crude opinions as to their fitness, to influence his attention to them. A failure in one particular may render an otherwise judicious treatment dangerous, and even fatal." History recapitulates that until the early 20th 
century, the physician has always sought to work according to moral precepts and ideals, in spite of social and cultural variables.

In contrast, AMA's opinion in 1990 on "Fundamental Elements of the Patient-Physician Relationship" now states a radically different position:

"The patient has the right to make decisions regarding the health care that is recommended by his or her physician. Accordingly, patients may accept or refuse any recommended medical treatment."

Progressively since then, patient autonomy has been conceptualized as the most important ethical principle in medical practice. ${ }^{13,14}$ It is conceived largely as a moral and legal defence against physician paternalism and against those who would impose their values-be it social, moral, or otherwise-upon others. The patient and physician relationship is seen as a contract and not as a covenant of care as it was in the past.

\section{Definitions of Informed Consent}

Informed consent (IC) is a form of social contract in which a physically mature and sane individual acknowledges both the benefits and risks of the proposed course of action/treatment, alternatives to the suggested treatment (including the option of no treatment) after being educated and without coercion from others. It is governed by four basic principles: autonomy, beneficence, non-malfeasance and justice, which have emerged as the universally accepted norms of medical ethics. ${ }^{15}$

The principle of autonomy refers to the patient's right to make free decisions about his or her health care based on their own values and beliefs. Applying this concept to the medical setting means that a competent adult has the right to make decisions about what happens to his body and any medical intervention should be done only after he is given sufficient information to help him make informed decisions. The granting of autonomy requires that we recognize and accept the free choice of each person even if that choice seems inappropriate or even life-threatening. This western view of autonomy is not universally accepted.

The principle of beneficence, on the other hand, emphasizes the moral importance of doing what is best for the patient. This principle is often interpreted as what a relevant health professional considers best for the patient whereas respect for autonomy identifies what the patient subjectively considers to be in his/her best interest. However it raises the question of as to who should be the adjudicator, as these two principles can potentially come into conflict when a mentally competent patient chooses a course of action which is not in his/her best interests as laid out by the caregiver.

The principle of non-malfeasance guides physicians to making decisions that maximize the benefit to patients whilst minimizing harm. The principle of justice demands fair, equitable, and appropriate treatment for all patients without discrimination due to sex, race, belief, political affiliation, social or other considerations as well as just distribution of medical resources. Adherents to these four principles approach them as equal in importance, and all as prima facie binding stipulations. However, Western liberals view autonomy as the most important ethical principle, superseding all others. $^{16,17}$

The Predominant Secular (Western) Model vs. the Islamic Model

The Western secular model of bioethics was a modern phenomenon which had its primordial origins in the West as a backlash against the perceived authoritarianism of the Church. It was grounded in secular, philosophical principles relying on human reasoning alone and without any religious contribution. Some secular advocates considered following divine law as detrimental for the people and that religion in general had no right to interfere with science and technology. ${ }^{18}$ Hence any moves to censor basic scientific research on moral, political and social grounds were resisted. There is no concept of the hereafter, therefore negating any notion of divine culpability in dealing with resources, environment, and life. They exert that that the universe self-exists and is not created, with man being a product of evolution and part of nature. Western epistemology denies revelation as a source of knowledge. Its scientific epistemology is solely based on matter and is therefore incomplete. It also denies morality as a factor in its work. It operates in a presumed moral vacuum where there is no recognition of absolute morality.

Accordingly, autonomy and self-determination are fundamental components of human dignity and rightness or wrongness of choice is reduced to the single factor of an individual's choice. Within such a paradigm, of course sexual acts between any consenting adults, abortion, contraception, divorce, one's right to euthanasia and suicide are seen as acceptable variations of the norm and secular bioethics does not offer any limits. The concept of life revolves around and emphasizes materialism. Happiness is defined as the accumulation of everincreasing material assets and the satisfaction of individual wants and needs at the expense of family, society and religion. The interests and welfare of the individual have priority over that of the society and maximizing the quality of life is the key to most bioethical decisions. ${ }^{19}$ It can be described as rightsbased with a strong emphasis on individual rights, namely the freedom of each individual to determine his/her own fate.

This model is not wholly effective because issues arose that required moral considerations and the secular law could not deal with them since it divested itself of 'religious' elements. The four principles have often been criticised due to their lack of any systematic relationship to each other 
and their frequent contradictions. Their reasoning is weak and inconsistent because there is no unified moral theory from which they are all derived. ${ }^{20}$ Sociologically, pluralism has persisted and indeed may have intensified. Further, this model is neither legally enforceable by the authority of the state nor morally enforceable by conscience.

The Islamic model, on the other hand, is based on the uncompromising concept of the unity of God (Allah), the Creator and Sustainer. A universal foundation of belief and practices creates a monotheistic culture, the aim of which is to create peace in one's self, family, and society by actively submitting to and implementing the will of God (Allah). Bioethical decision making is carried out within a framework of values derived from Islamic law (Shari'a), which draws its resources from revelation. ${ }^{21}$ The first is the Qur'an, the word of God revealed to Prophet Muhammad (SAW), which encompasses all facets of human life. The second is the Sunnah-the aspects of Islamic law based on the Prophet Muhammad's (SAW) words and actions as the messenger of God, who complemented and exemplified the Qur'anic message. The third is Qiyas, analogical reasoning when no clear rule is found in the Qur'an or Sunnah and the fourth is Ijma, the concerted effort and study of Islamic principles to derive legal opinions from the law by the community of scholars to a legal and practical issue. So this model is value-based, and holistic under the monotheistic, religious (tauhid) paradigm.

Morality and ethics in Islam are absolute and are of divine origin. While it incorporates various philosophical traditions, it draws its resources mainly from the religious texts. ${ }^{22}$ It is based on a complete system of morality which is the major influence on all public and private activities. Islamic law automatically bans all immoral actions as "Haram-disallowed" and permits all what is moral as Mubaah-allowed. Religion defines the role of the individual, the family, and the physician in all spheres of life, including birth, illness, and death. There is no separation between state and religion, and no activity is considered purely secular in the life of a Muslim. ${ }^{23}$ Islamic bioethics is based on duties and obligations (e.g., to preserve life, to seek treatment) and social responsibility.

Therefore, in Islamic context, the primacy appears reserved for the principle of public benefit and the collective interest takes precedence over that of the individual autonomy. ${ }^{21}$ Furthermore, the family often remains the important subject for the patient's decisions in difficult situations. Duties, rather than rights, are the central consideration in contrast to Western ethical approach, whose basis is exercising ones rights. Its instructions are aimed at the general welfare of all mankind and morality overrides all material benefits that a Muslim stands to gain. It prescribes for a balanced way of life and rejects extremism in living one's life in both its materialistic and spiritual aspects. Happiness is defined as obtaining the Creator's reward as humans will be held accountable for their deeds in the Hereafter. The concept of tauhid motivates the Physician to view the patient as an individual rather than a client, considering physical, social, psychological, and spiritual dimensions in treating a disease.

The Islamic model is universal, all-embracing, flexible, and allows for growth and development of various methods of investigating and treating diseases. It has an innate dynamism for incorporating any newly arising scenario or innovation into the corpus of the law. ${ }^{21}$ For example, necessity overrides prohibition-that is, if there are certain items which are prohibited in Islam, under dire necessity they can become permissible temporarily for as long as necessity is removed. Examples are insulin from pork or medications with alcohol. A similarity in basic principles can also be seen in Hippocrates' dictum "Primum non nocere" (first do no harm) when compared with to the widely applied principle of Shari'ah law - 'la darar wala dirar' - 'there shall be no harm inflicted or reciprocated,' which applies to all aspects of human life. One of the basic purposes of Islamic law is to minimize the risk of harm to individuals and the society and avoid everything that adversely affects them, otherwise known contemporarily as non-malfeasance. The difference is that in Islam beneficence and nonmalfeasance may supersede autonomy in certain instances. This is exemplified by the promulgation that "if a less substantial instance of harm and an outweighing benefit are in conflict, the harm is forgiven for the sake of the benefit." Accept the lesser of the two harms if both cannot be avoided (abortion in risk to the pregnant woman).

Islam emphasizes seeking knowledge and conducting research that are useful and responsive to the five purposes of Islamic Law (maqāsid al-sharīa - purpose of the sharia) which, in their order of importance are (1) protection of an individual's belief (faith), (2) protection of human life (3) maintaining the intellect (4) protecting the generation (family) and (5) protection of property (resources, nature, and environment). Any medical action must fulfil one of the above purposes to be considered ethical. ${ }^{24}$

Islam encourages individuals to get involved in such research, which has a public benefit and is of sufficient importance to justify the risks of participation. $.^{25}, 26$ Islam stresses the importance of learning, encourages cleanliness and personal hygiene, inculcates discipline and respect for authority, forbids destruction, tolerates other religions and celebrates diversity. Ethics is an indivisible part of Islamic law and most western basic principles of medical ethics are consistent with instructions found in Islam. A number of researchers have even suggested that these principles have always existed in Islam, but that 
their interpretation and practical application may differ. ${ }^{25}, 26$

\section{DISCUSSION}

Respect for patient autonomy is now widely accepted as imperative in the practice of medicine and clinical research over the last 3 decades. This concept applies well in securing the rights of patients against paternalistic infringement and in cases of malpractice. In addition, some studies have shown that patients who get an opportunity to exercise autonomy and who understand the reasons for a course of treatment are more likely to follow its prescriptions and it improves their psychological health. Further there are important differences between practice of medicine and clinical research. In our daily practice patients seek medical attention because they are sick and medical practitioners are formally trained and licensed. So the aim of the interaction is to benefit the individual patient rather than patients in general. ${ }^{29}$ Although it has been suggested that autonomy should be the governing principle of physician-patient relationships, it is on the whole the scope of autonomy where the conflict lies. ${ }^{30}$

Islam acknowledges the principle of autonomy as God (Allah) declared man as His viceroy on earth and said: "We have honoured Adam's children." 31 Islamic jurisprudence acknowledges autonomy as stipulated by the assertion that no one is entitled to dispose of the right of a human being without his/ her permission. ${ }^{27}$ They are endowed with reason and freewill and therefore are responsible for their actions. For example, in the Qur'an, we read, “The truth is from your Lord, so let him who please believe, and let him who please disbelieve' (Q: 18:29). Again we read "there is no compulsion in religion." (Q: 11:256). However the right to selfdetermination, while highly regarded, is not absolute in Islam as human actions, hence freedoms are curtailed by law, public and individual conscience. Islam seeks a balance between these three concentric circles. Consequently, personal choices are only accepted if they are the "right" ones. Individual autonomy is subservient to the larger good of the community and public interests take precedence over individual's private considerations. ${ }^{27,} 28$

This is in contrast to the United Nations Educational Scientific and Cultural Organization (UNESCO) declaration that promulgates the interests and welfare of the individual should have priority over the sole interest of science or society. ${ }^{19}$ Furthermore, the concept of autonomy in Western culture emphasizes individualism over the community, self-reliance over dependence, personal satisfaction, and self-actualization. ${ }^{32}$ People have the right to do whatever they wish with their bodies. ${ }^{33}$ The same argument is used in favour of physician-assisted suicide. ${ }^{34}$ Many
Westerners justify it by insisting that they are fundamental components of human dignity. Elderly people may request for euthanasia due to depression, hopelessness and other related symptoms. This desire frequently reverses over time, with appropriate treatment and social support. ${ }^{35,36}$ Moreover, euthanasia is not primarily an individual issue, rather a societal one. An individual's autonomy cannot be adhered to if it is causing direct harm to another or several other human beings. We have duties to those close to us, and therefore many believe that relational autonomy is more justified as opposed to individual autonomy.

Islam does not permit man to act as he wishes but limits him with certain rules. Muslim patients can make their own choices and decisions about medical care and treatment within the defined limitations of the Islamic law (Sharīah). Saving a human life is one of the most appreciated good deeds in Islam and the unwarranted taking of life a grave $\sin ^{37,38}$ For Muslims; life is a sacred trust from God (Allah). It must be respected and protected with great care. Therefore, the right to self-determination, while highly regarded, is not absolute, and an individual cannot legally consent to or be assisted in his death by another party.

Islamic bioethics emphasizes health promotion and disease prevention. Enjoining of good and forbidding evil are obligatory actions (wājib) that should be followed by all Muslims. For example, in the Qur'an, we read: "Let there arise from amongst you, a band of people inviting to all that is good, enjoining what is right, and forbidding what is wrong. They are the ones to attain felicity." ${ }^{39}$ Therefore it is obligatory for Muslim physicians to dissuade or even prevent hazardous lifestyle and behaviours that undermine individual and collective well-being, such as sexual promiscuity, alcoholism, environmental pollution, illicit drug use, and smoking. ${ }^{40}$ These activities are confined within the sphere of personal autonomy in the West and are thus regarded as an individual's choice. ${ }^{41}$ In Islam, an individual's freedom of choice is constrained by the harm it causes to others. Here again, the individual's autonomy is denied by the Islamic injunction on non-malfeasance. Being beneficent to others is an act of worship, since it is commanded by God (Allah) as well as by the Prophet Muhammad (SAW), who is reported to have said: He who alleviates the suffering of a believer out of the sufferings of the world, Allah (SWT) would alleviate his suffering from the sufferings of the Day of Resurrection.

Further autonomy makes sense in the context of a well-informed adult of sound mind. However patients' characteristics may affect the purpose of the informed consent and practical problems arise in explaining medical information and treatment alternatives even with relatively educated people. Resource limitations pose further problems, 
especially in developing countries where limited staff does not have enough time to comply with international standards of IC. Furthermore, it can be impinged upon by patient's condition whose competence may be temporarily compromised by fever, shock, medication, etc. or because they are minors, imprisoned, or have a cognitive impairment. Even some of us, in certain situations, are unable to make autonomous decision. The more complex the choice and the more impaired our ability to understand, the less we are likely to be able to make an autonomous decision. Further autonomy requires an appropriate relationship between patient, family and physician. In Islam the institution of the family is very strong who are intrinsically linked with each individual's wellbeing. This is especially true when somebody is seriously ill or at the end of his/her life. Consequently, decision making is family centred and beneficence and non-malfeasance play a dominant role. A physician or family member's advice should not be viewed as contrary to patient's autonomy under such circumstances. The proviso is that there should be open communication between all stakeholders with mutually agreed goals. Nonetheless, any preferences contained in an advance directive should take precedence over the views of the family. ${ }^{42}$ Therefore the obligation of respecting autonomy, though ample, is not possible at all times.

Furthermore many ethicists view autonomy as the most important ethical principle, which supersedes all others. It however lacks a constructive notion of physician-patient interaction when it is meant to promote the patient's best interest, which in essence is the application of the principle of beneficence. For example, a patient who has had bypass surgery may want to continue to smoke or a patient with bacterial meningitis may refuse antibiotics. Other examples concern a patient's right to demand treatment that the patient wants but that the physician thinks is unnecessary, inappropriate or even harmful. In these situations the autonomous choice of the patient conflicts with the physician's duty of beneficence and following patient's decision may cause the deprivation of the required health care. Physicians are needed to provide information and to discuss this information with patients to enable and empower them to use their autonomy wisely.

This is essential if physicians are to fulfil their part of the covenant with society and with individual patients. Pellegrino, an emeritus professor of medical ethics at Georgetown University envisions beneficence as complementing autonomy, rather than competing with it. Daniel Callahan, a wellknown bioethicist, contemplates that the principle of autonomy has been taken to extremes, and that it should be restrained. For him, nothing is of greater importance than to regain "the moral commons in medicine," something that he believes has been lost in the late twentieth-century shift to autonomy. However role of religion and spirituality in health care has begun to be appreciated over the past decade and cultural competence has gained attention as a potential strategy to improve quality and eliminate racial/ethnic disparities in health care. ${ }^{43}$ It is hoped that religion can offer an alternative model in bioethical decision making between patients and physicians with shared traditions, values and commitments. For both the patient and the physician character development of the moral agent has been sorely missed in the secular approach.

Due to rapid globalisation medical practice has become multicultural and diverse. Cross-cultural conflicts are reported at an exponential rate in the West, and they are already aware of the need to reexamine their social institutions. ${ }^{44} \mathrm{~A}$ flexible system considering cultural differences in the concept of autonomy may be more feasible than a system following strict universal norms. Further autonomy must be balanced against other ethical principles, such as beneficence, nonmaleficence, justice, integrity and solidarity, thereby recognising the interdependency and the interconnection of individuals within society. Fortunately the tide is changing and more bioethicists, despite their secularist tendencies, now insist that clinicians should be sensitive to the religious differences of their patients.

\section{CONCLUSION}

The concept of a unified standard of medical ethics will probably not be feasible in the near or distant future due to the difference in modes of bioethical reasoning, and the differing historical circumstances and viewpoints. Bioethics needs to expand its vision and acknowledge cultural variations and moral traditions of other cultures. Although autonomy remains a central tenet of bioethics, it should not be the absolute prerogative of the patient but rather a shared responsibility between the patient, family, and the physician. Promoting patient autonomy does not mean that the physician's expertise should be ignored or disregarded; rather Physicians' participation and beneficence enhance a patient's ability to make an autonomous decision. It should revolve around a mutually agreed upon common objective, taking into account the patient's cultural, psychological, and spiritual needs. The final decision though, must be taken by the person concerned.

\section{Acknowledgements}

This study was funded by research management centre International Islamic University Malaysia (EWD A 11-285-1076).

\section{REFERENCES}

1. Eisenberg DM, David RB, Ettner SL, et al. Trends in alternative medicine use in the United States. JAMA1998; 280:1569-75.

2. Justo L, Villarreal J. Autonomy as a universal 
expectation: a review and a research proposal. Eubios J Asian Int Bioeth 2003; 13:53-7. Available from http://www.eubios.info/EJ132/ ej132j.htm.

3. Butt L. The suffering stranger: medical anthropology and international morality. Med Anthropol. 2002; 21:1-24; discussion 25-33.

4. Turner L. From the local to the global: bioethics and the concept of culture. J Med Philos. 2005; 30:305-20.

5. Al Husseini, Dana I. "The Implications of Religious Beliefs on Medical and Patient Care." (2011). http://repository.upenn.edu/ od_theses_msod/46

6. Curlin, Farr A., Ryan E. Lawrence, Marshall H. Chin, and John D. Lantos. 2007. Religion, conscience, and controversial clinical practices. New England Journal of Medicine 356: 593-600.

7. Curlin, Farr A. A case for studying the relationship between religion and the practice of medicine. 2008. Academic Medicine; 83(12): 1118-1120.

8. Porter R. Greatest benefit to mankind: A medical history of humanity. New York: Norton WW \& Company, Inc, 1998.

9. Beaucamp TL: Informed consent: its history, meaning, and present challenges. Camb Q Healthc Ethics 2011, 20:515-523.

10. Hall DE, Prochazka AV, Fink AS: Informed consent for clinical treatment. CMAJ 2012, 184(5):533-540.

11. J. B. Dossetor, Beyond the Hippocratic Oath: A Memoir on the Rise of Modern Medical Ethics, University of Alberta Press, Edmonton, Canada, 2005.

12. Chin JJ. "Doctor-patient relationship: from medical paternalism to enhanced autonomy" Singapore Med J, Vol. 43 (3) (2002) 153-155.

13. Da Rocha A., "Back to basics in bioethics: reconciling patient autonomy with physician responsibility", Philosophy Compass. 4(1) (2009) 56-68.

14. Murray E, Lo B, Pollack L, et al. The impact of health information on the Internet on health care and the physician-patient relationship: national U.S. survey among 1,050 U.S. physicians. J Med Internet Res. 2003; 5:e17. http://dx.doi.org/10.2196/jmir.5.3.e17.

15. Beauchamp, T. and F. Childress. 2008. Principles of Biomedical Ethics. 6th Edition. Oxford: Oxford UP.

16. Callahan D. Principlism and communitarianism. J Med Ethics. 2003; 29(5):287-291.

17. Engelhardt HT Jr. The Foundation of Bioethics. 2nd ed. New York, NY: Oxford University Press; 1986:104.

18. Shlomi Tal. Necessity and primacy of secularism. Institute of secularization of I s I a m i c So c i e t y $\quad\left(\begin{array}{llll}2 & 0 & 0 & 1\end{array}\right)$ http://www.secularislam.org/separation/tal.ht $\mathrm{m}$

19. United Nations Educational, Cultural and Scientific Organization (UNESCO). Universal
Declaration on Bioethics and Human Rights. Paris: UNESCO; 2005. Available from http: / / www. unesco.org/new/en/social andhuman-sciences/themes/bioethics/ bioethics- andhuman-rights/.

20. Clouser D, Bernard G. A critique of principlism. J Med Philos. 1990; 15:219-36. Available from http://jmp.oxfordjournals.org/content/15/2/21 9.

21. Daar AS, al Khitamy AB. Bioethics for clinicians: 21. Islamic bioethics. CMAJ 2001; 164: 60-3.

22. Padela Al. Islamic medical ethics: A primer. Bioethics 2007; 21:169-78.

23. Nanji AA. Medical ethics and the Islamic tradition. J Med Philos. 1988; 13: 257-75. Available from http://jmp. oxfordjournals.org/content/13/3/257.

24. Kasule $\mathrm{OH}$. Medical ethics from Maqasid AlShariat. Paper presented at the international Scientific Convention jointly organized by the Jordan Society for Islamic Medical Studies, the Jordan Medical Association and the Federation of Islamic Medical Association at Amman, Jordan 15-17 July; 2004.

25. Fadel $\mathrm{H}$ E. Ethics of clinical research: an Islamic perspective. J Islam Med Assoc. 2010; 42:5969. Available from http://jima. imana.org/article/view/5512.

26. Weijer C, Dickens B, Meslin EM. Bioethics for clinicians: 10. Research ethics. CMAJ. 1997; 156: 1153-7. Available from http://www.cmaj.ca/ cgi/reprint/156/8/1153.

27. Aksoy S, Elmali A. The core concept of the four principles of bioethics as found in Islamic tradition. Med Law 2002; 21:211-24.

28. Aksoy S, Tenik A. The 'four principles of bioethics' as found in 13th century Muslim scholar Mawlana's teachings. BMC Med Ethics. 2002; 3:E4. Available from: http://dx.crossref. org/10.1186\%2F1472-6939- 3-4.

29. Lewens T: Distinguishing treatment from research: a functional approach. J Med Ethics 2006, 32:424-429.

30. Katz J: The silent world of doctor and patient. Baltimore: John Hopkins University Press; 2002.

31. The Glorious Qur'an, Chapter 17, Verse 70.

32. Alexander M. Capron, LL. Informed Consent in Catastrophic Disease Research and. Treatment, 123 U. PA. L. REV. 340, 364-76 (1974).

33. Harris J. The value of life: an introduction to medical ethics. London: Routledge; 1985.

34. Branch JA. Autonomy and the health sciences: clarifying a broad concept. Intégrité. 2003;2: 2033.

35. Wilson KG, Scott JF, Graham ID, Kozak JF, Chater S, Viola RA, et al. Attitudes of terminally ill patients toward euthanasia and physician-assisted suicide. Arch Intern Med 2000; 160:2454-60.

36. Blank K, Robison J, Doherty E, Prigerson $H$, Duffy J, Schwartz HI. Life-sustaining treatment and assisted death choices in depressed older patients. J Am Geriatr Soc 2001; 49:153-61.

37. Hedayat KM, Pirzadeh R. Issues in Islamic 
biomedical ethics: a primer for the pediatrician. Pediatrics. 2001; 108: 965-71.

38. The Glorious Qur'an, Chapter 4, Verse 29.

39. The Glorious Qur'an, Chapter 3, Verse 104.

40. The international Islamic code for medical and health ethics. Kuwait: Islamic Organization for Medical Sciences; 2005; 2: 121-276.

41. Ip M, Gilligan T, Koenig B, Raffin TA. Ethical decision- making in critical care in Hong Kong. Crit Care Med. 1998; 26: 447-51

42. Beauchamp TL, Childress JF. Princípios de ética biomédica. São Paulo: Loyola; 2002. 143: 284-6.

43. JR Betancourt, AR Green, JE Carrillo, ER Park Cultural Competence And Health Care Disparities: Key Perspectives And Trends. Health affairs, 2005; 24( 2): 499-505

44. Blackhall LJ, Murphy ST, Frank G, et al. Ethnicity and attitudes toward patient autonomy. JAMA. 1995; 274: 820-5. 